\title{
Circadian control of antigen-specific T cell responses
}

\author{
This article was published in the following Dove Press journal: \\ ChronoPhysiology and Therapy \\ I2 September 2016 \\ Number of times this article has been viewed
}

\author{
Chloé C Nobis ${ }^{1-3}$ \\ Nathalie Labrecque ${ }^{2-4}$ \\ Nicolas Cermakian ${ }^{1,5-8}$ \\ 'Douglas Mental Health University \\ Institute, ${ }^{2}$ Maisonneuve-Rosemont \\ Hospital Research Centre, \\ ${ }^{3}$ Department of Microbiology, \\ Infectious Diseases and Immunology, \\ ${ }^{4}$ Department of Medicine, University \\ of Montreal, ${ }^{5}$ Department of \\ Psychiatry, ${ }^{6}$ Department of \\ Microbiology and Immunology, \\ ${ }^{7}$ Department of Neurology and \\ Neurosurgery, ${ }^{8}$ Department of \\ Physiology, McGill University, \\ Montreal, QC, Canada
}

\begin{abstract}
The immune system is composed of two arms, the innate and the adaptive immunity. While the innate response constitutes the first line of defense and is not specific for a particular pathogen, the adaptive response is highly specific and allows for long-term memory of the pathogen encounter. $\mathrm{T}$ lymphocytes (or $\mathrm{T}$ cells) are central players in the adaptive immune response. Various aspects of T cell functions vary according to the time of day. Circadian clocks located in most tissues and cell types generate 24-hour rhythms of various physiological processes. These clocks are based on a set of clock genes, and this timing mechanism controls rhythmically the expression of numerous other genes. Clock genes are expressed in cells of the immune system, including T cells. In this review, we provide an overview of the circadian control of the adaptive immune response, with emphasis on T cells, including their development, trafficking, response to antigen, and effector functions.
\end{abstract}

Keywords: circadian clock, adaptive immune response, T lymphocyte, antigen, cytokine, proliferation

\section{Introduction \\ The circadian system}

Many aspects of physiology in various organisms (eg, humans, rodents, insects, plants, and bacteria) follow a biological rhythm with a period of approximately 24 hours. These rhythms are called circadian rhythms and are of endogenous origin, as they persist in the absence of external timing cues.

Circadian rhythms are generated by molecular clocks, which are present in almost all tissues and cells in mammals. ${ }^{1}$ These clocks are composed of a set of clock genes (eg, Clock, Bmal1, Period, Cryptochrome, Rev-Erb, Ror genes) organized in transcriptional-translational feedback loops. ${ }^{2}$ The transcription factor complex CLOCK/ BMAL1 regulates positively the transcription of Per and Cry genes. After synthesis of the PER and CRY proteins, they form complexes that enter the nucleus to inhibit their own expression by suppressing the activity of CLOCK/BMAL1. In a second feedback loop, CLOCK/BMAL1 activates the Rev-Erb and Ror genes. ROR factors positively control the transcription of Bmall, whereas REV-ERB factors inhibit it by binding to the same DNA element but at different times of the day (Figure 1). These molecular feedback loops are also regulated by extensive post-transcriptional regulation (eg, at the level of messenger RNA splicing, stability, and translation, and protein modification, stability, and trafficking).
Correspondence: Nicolas Cermakian Douglas Mental Health University Institute, 6875 LaSalle Boulevard, Montreal, QC H4H IR3, Canada $\mathrm{Tel}+\mathrm{I} 514761613 \mid$ ext. 4936 Fax +I 5147623034 Email nicolas.cermakian@mcgill.ca 


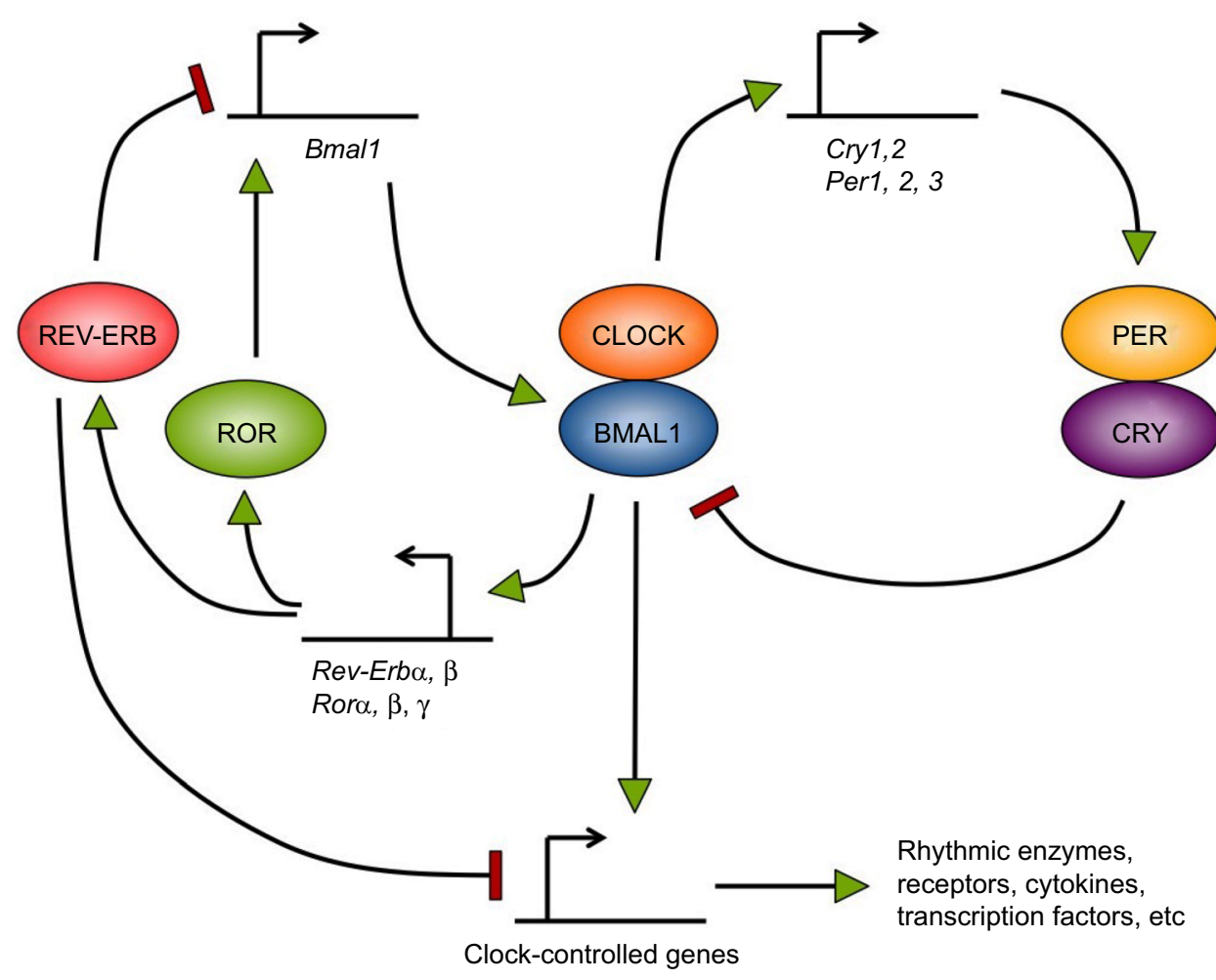

Figure I The basic circadian clock mechanism in mammals.

Notes: Most cells in the organism have a circadian clock, whose mechanism relies on a set of clock genes. The CLOCK/BMALI transcription factor complex positively regulates Per and Cry genes. PER and CRY proteins accumulate and then form complexes, enter the nucleus, and inhibit their own expression by repressing CLOCK/BMALI activity. In parallel, CLOCK/BMALI activates the Rev-Erb and Ror genes. ROR factors positively regulate Bmall gene expression, whereas REV-ERB factors repress it. Clock transcription factors, such as CLOCK/BMALI and REV-ERB $\alpha$, also regulate rhythmically the transcription of many other genes termed clock-controlled genes, which encode various types of proteins and constitute the output of the circadian clock.

This feedback loop mechanism leads to rhythmic expression of many of the clock genes. Moreover, these clock factors, whose transcriptional activity is higher at certain times of the day, regulate the expression of various genes in a timedependent manner. These clock-controlled genes can account for $5 \%-20 \%$ of any tissue's transcriptome. ${ }^{3}$ Transcriptomic studies on immune cells have shown that this is the case of genes in the immune system, as described later.

\section{The adaptive immune response}

Early protection against pathogens is mediated by the innate immune system, which therefore constitutes the first line of defense. It consists of physical barriers (eg, skin and mucosae) and cells that respond to broad groups of pathogens with processes that aim at killing these invaders. The adaptive immunity occurs generally when there is a lack of control of the pathogen growth by the innate immunity (Figure 2). In contrast to the innate immune response, the adaptive immune response is based on the specific recognition of antigens from pathogens.

$\mathrm{T}$ and $\mathrm{B}$ lymphocytes (or T and B cells) and antigenpresenting cells (APCs) (eg, dendritic cells) are the main actors of the antigen-specific immune response. These cells develop from a common progenitor located in bone marrow, and then migrate to various tissues to finish their development (in the case of $\mathrm{T}$ lymphocytes) and/or to control the immune response. $T$ cell development occurs in the thymus (a primary lymphoid organ). Mature $\mathrm{T}$ cells exit the thymus through blood and recirculate within secondary lymphoid organs (eg, spleen and lymph nodes) until they recognize, via their T cell receptor (TCR), a complex consisting of a major histocompatibility complex (MHC) molecule and an antigen peptide displayed at the surface of an APC. Two populations of $\mathrm{T}$ cells exist, which express either the CD4 or the $\mathrm{CD} 8$ membrane protein. The TCRs of $\mathrm{CD} 4^{+} \mathrm{T}$ cells interact with an MHC-II/peptide complex, whereas the $\mathrm{CD}^{+}$ T cell TCRs interact with an MHC-I/peptide complex. The specific interaction between the TCR and the MHC/peptide complex, the interaction between costimulatory molecules also expressed by these cells, and the cytokines secreted by them or present in the environment, altogether lead to the activation of $\mathrm{T}$ cells and to their massive expansion over the course of several days. The $\mathrm{T}$ cells then differentiate to become effector cells. Depending on the type of pathogen, 


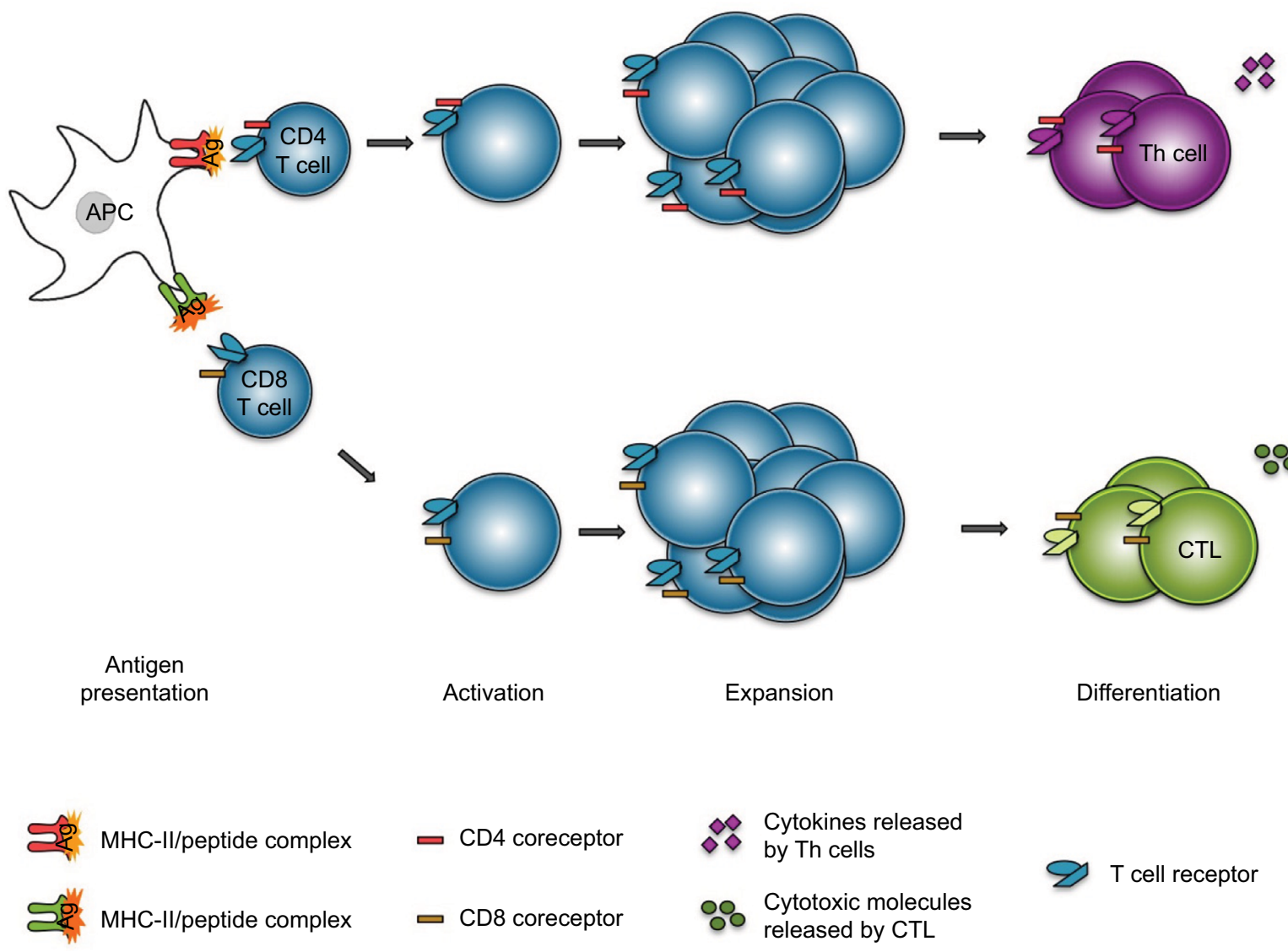

Figure 2 T cell response to antigen presentation.

Notes: APCs present antigen peptides at their surface in conjunction with MHC molecules. The MHC/peptide antigen complexes interact specifically with T cell receptors at the surface of $\mathrm{T}$ cells. Following this, the $\mathrm{T}$ cells become activated and proliferate (expansion stage). Depending on the pathogen and the location, CD4 ${ }^{+} \mathrm{T}$ cells will differentiate into one of the various Th cells, whereas CD8 ${ }^{+} \mathrm{T}$ cells will become CTL. All of these cells will express different cytokines, leading to the control of the infection. Abbreviations: APCs, antigen-presenting cells; CTL, cytotoxic T lymphocytes; MHC, major histocompatibility complex; Th, T helper.

activated $\mathrm{CD} 4^{+} \mathrm{T}$ cells differentiate into different types of helper T cells (Th cells): Th1 cells for intracellular pathogen elimination, Th2 cells for extracellular parasites, Th9/Th17 cells for fungi and extracellular bacteria. ${ }^{4,5}$ Another subset of $\mathrm{CD}^{+} \mathrm{T}$ cells, regulatory $\mathrm{T}$ cells (Treg), are responsible for the negative regulation of autoreactive T cells. ${ }^{6}$ As for $\mathrm{CD} 8^{+}$ $\mathrm{T}$ cells, they become cytotoxic after activation and produce a large range of cytotoxic molecules and proinflammatory cytokines (eg, perforin, granzyme B, and interferon gamma [IFN- $\gamma]$ ) to eliminate the infected cells. ${ }^{7}$

A fraction of activated $\mathrm{T}$ cells become memory cells after an interaction with a MHC/peptide complex displayed by an APC. These memory cells will intervene quickly during a subsequent infection with the same pathogen.

This review article focuses on the circadian control of the adaptive immune response, in particular, $T$ cell function. For a description of circadian rhythms in the innate response, the reader is referred to recent reviews ${ }^{8,9}$ As we will report subsequently, $\mathrm{T}$ cells show daily rhythms in their tissue and blood counts, their response to antigen presentation, and their differentiation and acquisition of effector functions.

\section{Clock gene expression in $\mathrm{T}$ cells and lymphoid organs}

Most tissues and cell types in mammals express clock genes. This includes secondary lymphoid organs such as the spleen and lymph nodes. ${ }^{10,11}$ For example, mouse lymph node cells express rhythmically Per 2 and Rev-Erb $\alpha$ genes with a maximum expression at CT14 and CT8, respectively. This rhythmic expression is blunted in $C l o c k \Delta^{19} \Delta^{19}$ mice (which express a dominant negative mutant version of the protein CLOCK) ${ }^{11}$ Lymph nodes are one of the main sites where the adaptive immune response is initiated. This organ is enriched in T- and B cells, which also express clock genes. ${ }^{12-14}$

Rhythmic clock gene expression was observed in splenic and thymic $\mathrm{CD}^{+} \mathrm{T}$ cells using tissues from PER2::Luciferase (PER2::Luc) reporter mice, which allows the analysis in real time of circadian dynamics in live tissues or cells. ${ }^{12,15}$ Rhythmic expression of Bmall and Rev-Erb $\alpha$ was blunted in $\mathrm{CD}^{+} \mathrm{T}$ cells from $\mathrm{T}$ cell-specific Bmall knockout (KO) mice compared to wild type (WT) mice, although it should be pointed out that even in WT mice the amplitude of the messenger RNA was lower than 
in the liver. ${ }^{16}$ Human $\mathrm{CD} 4{ }^{+} \mathrm{T}$ cells isolated from whole blood also express the clock gene rhythmically (eg, PER2, PER3, $R E V-E R B \alpha$, and $R O R \alpha){ }^{12}$ Thereby, similar to other immune cells, $\mathrm{CD}^{+} \mathrm{T}$ cells express circadian clock components. ${ }^{8,12}$ Whether CD8+ T cells also have a circadian clock remains to be elucidated. The presence of clock mechanisms in lymphoid organs and in T cells raises the question of what their impact is on the adaptive immune response. This has been addressed by a number of recent reports, which we describe subsequently.

\section{T cell development Clock gene expression in the thymus}

Lymphoid progenitors present in the bone marrow migrate to the thymus, where they continue their development and become mature T cells. In the thymus, thymocytes ( $T$ cell precursors) then need interactions with stromal thymic epithelial cells to shape their TCR and, therefore, increase the capacity of $\mathrm{T}$ cells not only to recognize a large range of pathogens, but also to eliminate autoreactive T cells (ie, T cells that must be eliminated because they could recognize self-antigens). ${ }^{17,18}$ These stages are named the positive and the negative selection. During the positive selection, the interaction between the TCR and the MHC molecule on stromal epithelial cells is essential for the survival of T cells. Then the thymocytes migrate to the thymic medulla to go through the negative selection. During this stage, a strong interaction between the TCR and the MHC-self-antigen complex on stromal thymic epithelial cells leads to the elimination of T cells. The other $\mathrm{T}$ cells become mature and leave the thymus.

Studies on the mouse thymus showed expression of clock genes that is not rhythmic. ${ }^{19-21}$ This expression in the thymus is not affected in $C l o c k^{\Delta 19 / \Delta 19}$ mice, suggesting that this organ does not bear a clock. However, in one report, a robust rhythm of luciferase activity was observed for more than 4 days in a cultured thymic slice from a PER2::Luc mouse. The rhythm observed in these experiments could be due to the stromal thymic epithelial cells rather than the mature T cells or thymocytes in the thymus. However, using the same mouse model, mouse mature splenic and thymic $\mathrm{CD}^{+} \mathrm{T}$ cells presented a bioluminescence rhythm (ie, luciferase reporter rhythm), leading to conclude that mature $\mathrm{CD}^{+} \mathrm{T}$ cells have a clock. ${ }^{12}$

\section{Cell division in the bone marrow and the thymus follows a circadian rhythm}

After some of the steps of T cell development, the thymocytes proliferate. The calcium homeostatic system plays an important role in this proliferation and cell division. ${ }^{22}$ Thereby, in the plasma of male rats, the total and ionized calcium concentrations (the latter being the biologically active form) follow a daily rhythm, with a minimal concentration before the activity phase (dark phase). ${ }^{23}$ This is positively correlated with the bone marrow and thymus mitotic index. These results suggested that the daily change of calcium concentration in plasma could be involved in the rhythmicity of the cell division in the bone marrow and the thymus of rats. The results were confirmed by the removal of the parathyroid glands, which are involved in regulating the calcium concentration. Indeed, the rhythm of bone marrow and thymus mitotic index was abolished after this ablation. ${ }^{23}$

To undergo cell division, cells need to synthetize DNA. One way to monitor DNA synthesis is by measuring the uptake of ${ }^{3} \mathrm{H}$ thymidine. In the mouse thymus, ${ }^{3} \mathrm{H}$ thymidine uptake is rhythmic: the minimum of the uptake occurs during the beginning of the activity period, which is in agreement with the rhythm of plasma calcium concentration and bone marrow and thymus mitotic index observed in rats (see previous paragraph). ${ }^{23,24}$

\section{$T$ cell recirculation and numbers Circadian variation of $T$ cell numbers in the blood}

After their maturation in the thymus, naive mature $\mathrm{T}$ cells recirculate between the secondary lymphoid organs through the peripheral blood and lymph. Several studies conducted in human subjects showed that $\mathrm{CD}^{+}$and $\mathrm{CD} 8^{+} \mathrm{T}$ cells peak during the night in peripheral blood. ${ }^{6,25-28}$ In rodents, the $\mathrm{T}$ cell counts in the blood vary over 24 hours and persist when the rats are in a constant condition (eg, constant darkness or constant light), which leads to the conclusion that it is a circadian (endogenous) rhythm. ${ }^{29}$

In humans, the daily rhythms of $\mathrm{T}$ cell subsets change across life and in the context of disease. For example, the number of $\gamma \delta \mathrm{T}$ cells in the blood was still rhythmic, but delayed by several hours in patients with lung cancer. ${ }^{30}$ The amplitude was also decreased. Similar amplitude changes for this $T$ cell subset were observed in elder subjects compared to young subjects. ${ }^{30}$ The amplitude of the rhythm of CD8+ $T$ cell numbers in the blood was also reduced in elder subjects and in patients with lung cancer. ${ }^{30,31}$

\section{Cortisol controls the daily variation of $T$ cell numbers in the blood}

Several human and rodent studies have highlighted a negative correlation between $\mathrm{T}$ cell numbers in peripheral blood 
and plasma cortisol (Figure 3). ${ }^{6,26-28,32,33}$ Indeed, blood T cell counts peak at night and start decreasing in the early morning simultaneously with increase of plasma cortisol. To test the direct effect of cortisol on $\mathrm{T}$ cell counts, prednisolone (a synthetic corticosteroid) or cortisol was administered to human subjects, which led, in both cases, to the decrease of $\mathrm{T}$ cell numbers in the blood. ${ }^{28,34}$ In contrast, infusion of epinephrine, which is also negatively correlated with the total $\mathrm{T}$ cell blood counts, increased the number of effector $\mathrm{CD} 8^{+} \mathrm{T}$ cells, which constitute the only $\mathrm{T}$ cell subset that peaks in the day. ${ }^{28}$ These results were supported by rodent studies. ${ }^{35,36} \mathrm{In}$ mice that do not synthesize corticosterone (following surgical ablation of the adrenal glands), the circadian variation of T cell numbers, which normally has a peak at the beginning of the light phase in the blood and spleen, was abolished.

A possible mechanism for the action of glucocorticoids on $\mathrm{T}$ cell blood counts came from a study showing that hydrocortisone treatment in mice induced a sequestration of peripheral $\mathrm{T}$ cells in the bone marrow. ${ }^{35}$ More recent human studies suggested a regulation by chemokine receptor expression in T cells. CXCR4 is a chemokine receptor involved in the migration of $\mathrm{T}$ cells and $\mathrm{B}$ cells in bone marrow in response to the chemokine CXCL12. CXCR4 expression in T cells was shown to be higher in the morning than in the evening. ${ }^{28}$ Moreover, cortisol treatment increased its expression on the surface of T cells. ${ }^{28}$ Furthermore, oral intake by human subjects of metyrapone, an inhibitor of cortisol synthesis, resulted in the suppression of the morning decline of T cells in the blood and in parallel, it abolished the morning increase of CXCR $4 .{ }^{37}$ These studies suggest a circadian control of the number of $\mathrm{T}$ cells in peripheral blood by plasmatic cortisol, which plays a role in the homing of $\mathrm{T}$ cells in different tissues according to the time of the day.

The rhythm of $\mathrm{T}$ cell numbers in peripheral blood could also be explained by the intervention of the autonomic nervous system. ${ }^{38}$ Indeed, in humans, a subset of T lymphocytes presents a peak in the daytime and another subset in the nighttime: cells peaking in the daytime express higher levels of adrenergic receptors, whereas those peaking at night display more cholinergic receptors. ${ }^{38}$ However, more work would be needed to establish a causative link.

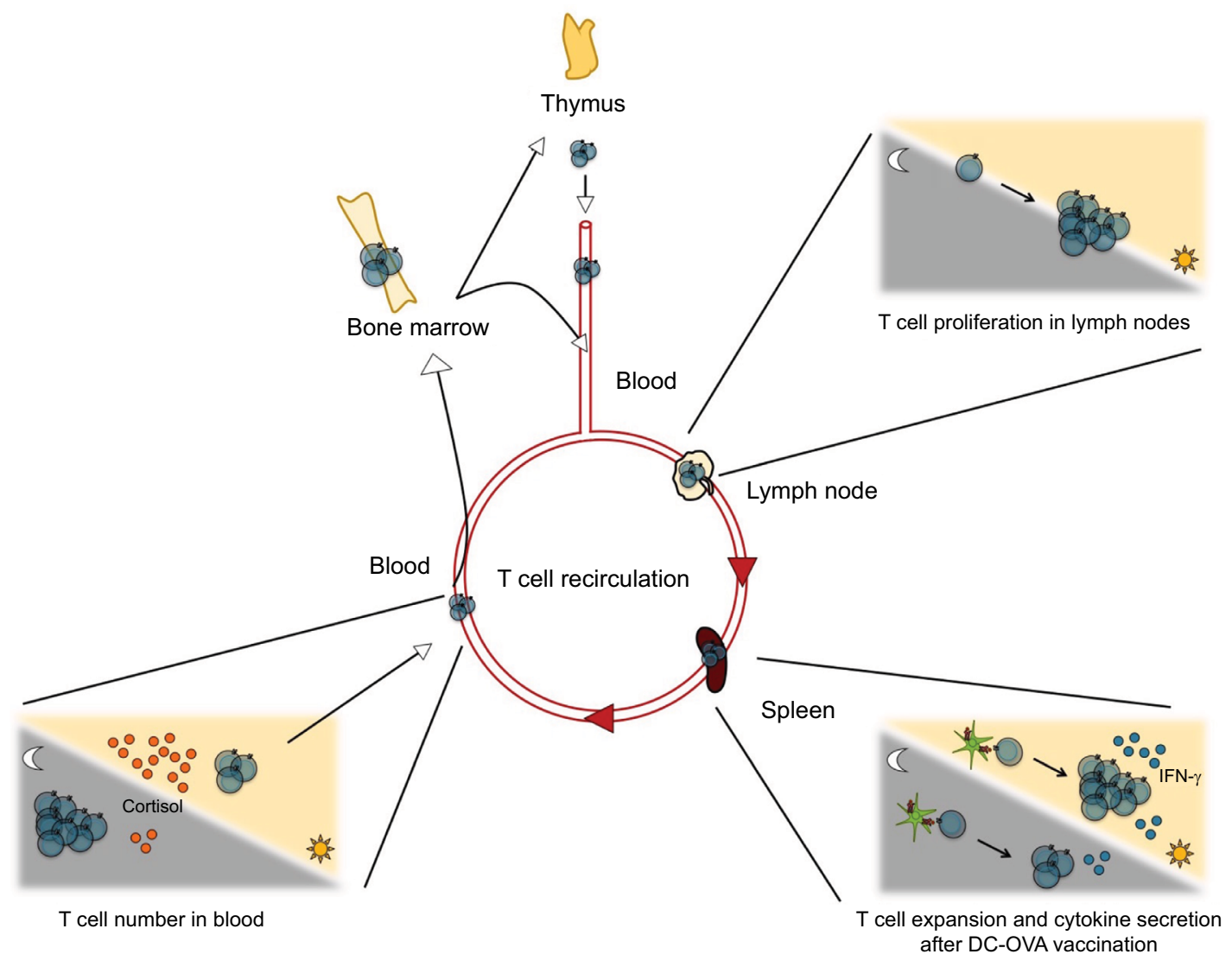

Figure 3 Circadian control of T cells.

Notes: Circadian clocks control T cell functions at various levels: number of cells in the lymphoid organs and in blood, proliferation in response to mitogenic signals or antigen presentation, differentiation in effector cells, and secretion of cytokines. Some examples of rhythms of $\mathrm{T}$ cell functions are depicted here. Abbreviation: DC-OVA, dendritic cells loaded with the OVA peptide. 


\section{Circadian control of the T cell activity}

The adaptive immune response follows a circadian rhythm

Several rodent and human studies showed that $\mathrm{T}$ cell responses to antigen-specific stimulation or nonspecific stimulation (eg, phytohemagglutinin [PHA], phorbol 12-myristate 13-acetate (PMA)/ionomycin stimulation) follow a circadian rhythm. ${ }^{11,12,39-41}$

Pioneer studies reported in 1976 suggested a circadian control of the antigen-specific immune response. ${ }^{39,41}$ Two things were tested: the in vitro reactivity in human mixed lymphocytes culture (a test with a mix of lymphocytes from two different donors, in which the different histocompatibility antigens at the cell surface will lead to the activation and proliferation of lymphocytes) and the blastogenesis in vitro in response to an antigen, streptokinase-streptodornase. In both cases, a variation was observed over 24 hours, but with different phases. ${ }^{41}$ Indeed, the mixed lymphocytes culture reactivity was higher in the late morning/early afternoon, whereas the antigen-specific immune response (streptokinase-streptodornase response) peaked during the night. ${ }^{41}$

Immunization of mice with sheep red blood cells every 6 hours over 24 hours led to more plaque-forming cells (which measure the quantity of a specific antibody against a specific antigen) when the immunizations occurred late night/early morning. ${ }^{39}$ These results are correlated with the ex vivo proliferation of splenocytes restimulated with PHA or Concanavalin A, where the proliferation response was higher when the mice had less plaque-forming cells. ${ }^{39}$ However, because this experimental procedure is based on a humoral immune response (antigen-specific response mediated by the production of antibodies by $\mathrm{B}$ cells), it remains to be elucidated whether $\mathrm{T}$ cells participate or not in this rhythmic response. Indeed, T cells are involved in helping B cells in antibody production.

Recent work using a model of mouse vaccination with APCs loaded with an antigenic peptide showed a day/ night variation of the antigen-specific immune response. ${ }^{11}$ Indeed, when the dendritic cells loaded with the OVA peptide (DC-OVA) were injected during the middle of the day, the expansion of $\mathrm{CD}^{+} \mathrm{T}$ cells specific for the antigen was higher than when DC-OVA were injected during the middle of the night. ${ }^{11}$

Altogether, these different studies suggest a circadian control of the antigen-specific immune response in humans and rodents.

\section{T cell proliferation follows a circadian rhythm}

The influence of circadian rhythms on $\mathrm{T}$ cell proliferation was studied in humans and rodents (Figure 3). In humans, plasmatic cortisol levels are correlated with the proliferation of T cells in response to the tetanus toxoid (TT).$^{42}$ Indeed, $\mathrm{T}$ cell proliferation was more efficient during early morning when the cortisol levels were low. ${ }^{42}$ Another report in humans highlighted a circadian rhythm of $\mathrm{CD} 4{ }^{+} \mathrm{T}$ cell reactivity to adenovirus and Staphylococcus aureus enterotoxin B (SEB) by measuring the percentage of cells secreting cytokines, such as IFN- $\gamma$ or interleukin 2 (IL-2) ${ }^{26}$ As for TT reactivity, the reactivity to adenovirus and SEB by $\mathrm{CD}^{+} \mathrm{T}$ cells occurred during early morning. ${ }^{26}$

In rats, the 24-hour mitogenic variations were analyzed after subcutaneous injection of Freud's adjuvant or vehicle. ${ }^{43,44}$ Lymph node cells were restimulated with Concanavalin $\mathrm{A}$, which activates the $\mathrm{T}$ cells by interacting directly with their TCR. T cell proliferation was higher during the light phase (the rest phase in rodents) in both young and old rats. Interestingly, the amplitude of the rhythm of $\mathrm{CD} 8^{+}$ $\mathrm{T}$ cell counts in submaxillary lymph nodes was decreased in old rats compared to young rats, whereas the $\mathrm{CD} 4^{+} \mathrm{T}$ cell rhythm was not altered. The rhythm of the proliferative response to Concanavalin A stimulation was dampened in old rats compared to young rats. These results suggest that there is a circadian control of the $\mathrm{T}$ cell response to a nonspecific stimulation dependent on various parameters, such as the age of the rodent.

In mice, $\mathrm{T}$ cell proliferation after anti-CD3 stimulation also follows a circadian rhythm. ${ }^{11}$ The highest level of proliferation was observed using cells taken from mice late in the day or at night. ${ }^{11}$ This is dependent on a circadian clock since the rhythm is abolished in $\operatorname{Clock}^{\Delta 19 / \Delta l 9}$ mutant mice.

\section{T cell cytokine secretion follows a circadian rhythm}

Activation of T cells by APCs leads them to secrete cytokines such as IL-2, involved in lymphocyte differentiation, immune responses, and homeostasis, and IFN- $\gamma$, involved in the recruitment of innate immune cells and in the activation and differentiation of $\mathrm{T}$ cells. This secretion of cytokines by $\mathrm{T}$ cells is regulated in a circadian manner. In human whole blood samples stimulated in vitro with TT or the purified protein derivative (a mixture of antigens of bacterial origin), IFN- $\gamma$ secretion by $\mathrm{T}$ cells was higher in the early morning. ${ }^{45}$ Another study showed that after stimulation with adenovirus 
antigen SEB, the percentage of IFN- $\gamma$-positive cells peaked during early night, whereas the IL-2-positive cells peaked during the middle of the night. ${ }^{26}$ Also, the number of CD4 ${ }^{+}$ IFN- $\gamma^{+} \mathrm{T}$ cells and the number of CD $4^{+} \mathrm{IL}-2^{+} \mathrm{T}$ cells and CD4 ${ }^{+}$ IL- $4^{+} \mathrm{T}$ cells were rhythmic after an ex vivo short stimulation with PMA/ionomycin. ${ }^{12}$ Notably, IFN- $\gamma$ protein expression levels were also rhythmic, which was not the case for IL-2 and IL-4 expression. ${ }^{12}$ Microarray analysis on $\mathrm{CD}^{+} \mathrm{T}$ cells stimulated with PMA/ionomycin at three different time points corresponding to the first maximum, the minimum, and then the second maximum of IFN- $\gamma$ production showed a time-dependent expression of genes involved in the NF-kB pathway, known to be important for cytokine secretion. ${ }^{12}$

The rhythmicity of $\mathrm{T}$ cell responses might have implications for shift workers. This was suggested by a recent study conducted in subjects under a simulated night shift schedule. ${ }^{46}$ Indeed, the PHA-induced secretion of IFN- $\gamma$ and IL-2 by $T$ cells was advanced by 5-6 hours, compared to their secretion in the same subjects under a prior day-oriented schedule. ${ }^{46}$ This was not due to a change in the rhythm of T cell numbers, which was not shifted under night shift. ${ }^{46}$ The rhythm of plasma melatonin was not shifted in simulated night shift subjects. Since melatonin is a marker of the central circadian clock in the suprachiasmatic nucleus in the hypothalamus, these data suggest that the central clock controls the rhythm of $\mathrm{T}$ cell numbers in blood, but not the cytokine secretion by $\mathrm{T}$ cells. ${ }^{46}$ Therefore, the mechanisms involved in the rhythmicity of blood $\mathrm{T}$ cell counts and cytokine secretion by $\mathrm{T}$ cells seem to be distinct. Because of this, night shift appears to induce desynchronization of different $\mathrm{T}$ cell rhythms.

To our knowledge, only two in vivo reports in mice showed that cytokine secretion is regulated in a circadian manner. ${ }^{11,16}$ In response to vaccination with DC-OVA, the percentage of IFN $-\gamma^{+} \mathrm{CD}^{+} \mathrm{T}$ cells 7 days postimmunization (the time of peak of the immune response in the context of DC-OVA vaccination) was higher when the vaccination occurred during the middle of the day than during the middle of the night (Figure 3). ${ }^{11}$ Interestingly, the percentage of IFN$\gamma^{+} \mathrm{CD}^{+} \mathrm{T}$ cells after Listeria monocytogenes infection in mice presented no day/night difference. ${ }^{16}$ In these experiments, the time points of infection and vaccination were different (beginning of the day and of the night for the bacterial infection vs middle of the day and the night for the DC-OVA vaccination), and therefore, it remains possible that the day/ night difference was not observed with the time points used for the infection experiment. ${ }^{11,16}$ However, the percentage of IL- $2^{+} \mathrm{CD}^{+} \mathrm{T}$ cells was higher after the infection with $L$. monocytogenes in the beginning of the day than in the beginning of the night. ${ }^{16}$ Importantly, this was the case both in WT mice and in mice with a Bmall gene deletion, specifically in T cells (ie, T cell-specific Bmall KO), suggesting that the $\mathrm{T}$ cell clock is not involved in the day/night difference of the percentage of IL- $2^{+} \mathrm{CD} 8^{+} \mathrm{T}$ cells observed after an infection.

\section{Circadian control of T cell subsets The ThI/Th2 balance is regulated in a circadian manner}

Th1 and Th2 cells are effector $\mathrm{CD} 4^{+} \mathrm{T}$ cells involved in different aspects of the adaptive immune responses. Indeed, Th1 cells are responsible for the elimination of intracellular pathogens, whereas $\mathrm{Th} 2$ cells are involved in the allergic reactions and in the clearance of extracellular pathogens and parasites.

Several groups have analyzed the circadian pattern of allergic immune responses and showed that most occur during night and in the early morning in humans, and are increased during the day in rodents. ${ }^{47,48}$ Therefore, it was not a surprise to observe that the Th1/Th2 cytokine balance is shifted toward Th2 cytokines during early sleep and the reverse occurs during late night in humans, and the effects are opposite in rodents. ${ }^{48,49}$ Indeed, in human peripheral blood mononuclear cells stimulated with PMA/ionomycin, the ratio between $\mathrm{Th} 1$ and $\mathrm{Th} 2$ representative cytokines (IFN- $\gamma$ and IL-4, respectively) was increased during sleep. ${ }^{49}$ In the context of food allergy, mice orally administered with OVA antigen during the light (ie, rest) period presented a higher secretion of type 2 cytokines, such as IL-13 and IL-5, in mesenteric lymph nodes than the mice of a night period-treated group. ${ }^{50}$

As mentioned before, glucocorticoids seem to be involved in the control of cytokine secretion. In the human studies described earlier, the Th1/Th2 ratio is lower in the early night/sleep phase and shifts toward Th1 cells by the end of the night, when the plasma cortisol is high. This suggests that glucocorticoids may favor Th1 responses. Accordingly, in another report where human blood samples were stimulated with PMA/ionomycin, cortisol treatment increased the IFN- $\gamma /$ IL-4 ratio in $\mathrm{CD}^{+} \mathrm{T}$ cells ${ }^{51}$ In contrast though, in one mouse study, after in vivo immunization with OVA antigen, the IL-2/ IL-4 cytokine balance was shifted toward IL-4 secretion in mice exposed to a constant low dose of dexamethasone, compared to nonexposed mice. ${ }^{52}$ 


\section{The clock machinery is important in ThI 7 cell development and function}

Th17 cells are important for the elimination of bacteria and fungal infections at mucosal surfaces. These cells are also involved in the development of autoimmune diseases, such as multiple sclerosis. A recent report highlighted the importance of the clock machinery in the Th17 cell development. ${ }^{53}$ In Nfil3 KO mice, Th17 cell numbers were increased in the small intestine and colon. ${ }^{53}$ The clock protein REV-ERB $\alpha$ was shown to negatively control Nfil3 expression. In the absence of REV-ERB $\alpha$, Nfil3 expression was derepressed, and therefore, Th17 cell development was increased. ${ }^{53}$

In the context of multiple sclerosis, a group showed control of the Th17/Treg development by the circadian hormone melatonin in mice. ${ }^{54}$ Melatonin acts on its receptor MT1 in Th17 and Treg cells, inducing the secretion of IL-10 by Treg cells and inhibiting Th17 cell development and IL-17 cytokine secretion, leading to a less severe pathology. ${ }^{54}$ Together, these two studies have highlighted the importance of the circadian clock in the development of Th17 and Treg cells.

\section{Treg numbers and function follow a circadian rhythm}

Treg cells negatively control the development of autoimmune diseases by suppressing the functions of autoreactive $T$ cells ( $T$ cells responding to self-antigens). Similar to $T$ helper cell subsets, Treg cells are regulated in a daily manner. A human report showed that the number of Treg cells in the blood was rhythmic and independent of sleep. ${ }^{55}$ However, the suppressive action of Treg cells on $\mathrm{T}$ cell function (eg, $\mathrm{T}$ cell proliferation and IL-2 secretion) was less efficient when the Treg cells came from donors with sleep deprivation. ${ }^{55} \mathrm{~A}$ second study measured the suppressive effect of Treg cells on Th1, Th2, and Th17 cells over 24 hours by analyzing cytokine secretion by these $\mathrm{T}$ cell subsets. ${ }^{56}$ Only cytokines produced by Th1 cells (IL-2, IFN- $\gamma$, and tumor necrosis factor alpha) had their secretion supressed differentially according to the time of day, with a maximal effect observed during early night. ${ }^{56}$ On the other hand, the suppressive effect of Tregs on the Th2 and Th17 cytokines did not vary according to time of day. These results are in agreement with the previous study showing the shift from Th2 to Th1 cytokine secretion during sleep, and suggest a possible mechanism for this shift. ${ }^{49}$

\section{Conclusion}

The link between the circadian system and the adaptive immune response is clearly established in humans as well as in rodents. Circadian regulation allows the organism to adapt to environmental variations in order to anticipate potential dangers, such as infections. Thereby, this circadian control was observed at various levels of the adaptive immune response, from $\mathrm{T}$ cell development in the thymus to the number of cells in blood and $\mathrm{T}$ cell activation by synthetic molecules or antigens. In many cases, the exact cellular and molecular mechanisms underlying the circadian control of $\mathrm{T}$ cell functions remain unclear. In particular, the nature and extent of the role of the T cell-intrinsic clock for different aspects of $\mathrm{T}$ cell functions will need to be investigated. Moreover, future research will allow defining the implications of these rhythms of T cell biology for the fight against pathogens and cancer cells, for the development of autoimmune diseases, and for the improvement of vaccination.

\section{Acknowledgments}

The authors thank the members of NC's laboratory for discussion. This work was funded by a Canadian Institutes for Health Research grant (MOP-119322) (to NC and NL).

\section{Disclosure}

The authors report no conflicts of interest in this work.

\section{References}

1. Dibner C, Schibler U, Albrecht U. The mammalian circadian timing system: organization and coordination of central and peripheral clocks. Annu Rev Physiol. 2010;72:517-549.

2. Duguay D, Cermakian N. The crosstalk between physiology and circadian clock proteins. Chronobiol Int. 2009;26(8):1479-1513.

3. Zhang R, Lahens NF, Ballance HI, Hughes ME, Hogenesch JB. A circadian gene expression atlas in mammals: implications for biology and medicine. Proc Natl Acad Sci U S A. 2014;111(45):16219-16224.

4. Mosmann TR, Cherwinski H, Bond MW, Giedlin MA, Coffman RL. Two types of murine helper $\mathrm{T}$ cell clone. I. Definition according to profiles of lymphokine activities and secreted proteins. J Immunol. 1986;136(7):2348-2357.

5. Tato CM, O'Shea JJ. Immunology: what does it mean to be just 17 ? Nature. 2006;441(7090):166-168.

6. Miyawaki T, Taga K, Nagaoki T, Seki H, Suzuki Y, Taniguchi N. Circadian changes of T lymphocyte subsets in human peripheral blood. Clin Exp Immunol. 1984;55(3):618-622.

7. Weninger W, Manjunath N, von Andrian UH. Migration and differentiation of CD8+ T cells. Immunol Rev. 2002;186:221-233.

8. Labrecque N, Cermakian N. Circadian clocks in the immune system. J Biol Rhythms. 2015;30(4):277-290.

9. Curtis AM, Bellet MM, Sassone-Corsi P, O’Neill LA. Circadian clock proteins and immunity. Immunity. 2014;40(2):178-186.

10. Keller M, Mazuch J, Abraham U, et al. A circadian clock in macrophages controls inflammatory immune responses. Proc Natl Acad Sci US A. 2009; 106(50):21407-21412.

11. Fortier EE, Rooney J, Dardente H, Hardy MP, Labrecque N, Cermakian N. Circadian variation of the response of T cells to antigen. J Immunol. 2011;187(12):6291-6300.

12. Bollinger T, Leutz A, Leliavski A, et al. Circadian clocks in mouse and human CD4+ T-cells. PLoS One. 2011;6(12):e29801. 
13. Silver AC, Arjona A, Hughes ME, Nitabach MN, Fikrig E. Circadian expression of clock genes in mouse macrophages, dendritic cells, and B cells. Brain Behav Immun. 2012;26(3):407-413.

14. Sun Y, Yang Z, Niu Z, et al. MOP3, a component of the molecular clock, regulates the development of B cells. Immunology. 2006;119(4):451-460.

15. Yamazaki S, Takahashi JS. Real-time luminescence reporting of circadian gene expression in mammals. Methods Enzymol. 2005;393:288-301.

16. Hemmers S, Rudensky AY. The cell-intrinsic circadian clock is dispensable for lymphocyte differentiation and function. Cell Rep. 2015;11(9):1339-1349.

17. Zuniga-Pflucker JC, Lenardo MJ. Regulation of thymocyte development from immature progenitors. Curr Opin Immunol. 1996;8(2): 215-224.

18. Anderson G, Moore NC, Owen JJ, Jenkinson EJ. Cellular interactions in thymocyte development. Annu Rev Immunol. 1996;14:73-99.

19. Alvarez JD, Chen D, Storer E, Sehgal A. Non-cyclic and developmental stage-specific expression of circadian clock proteins during murine spermatogenesis. Biol Reprod. 2003;69(1):81-91.

20. Alvarez JD, Sehgal A. The thymus is similar to the testis in its pattern of circadian clock gene expression. J Biol Rhythms. 2005;20(2):111-121.

21. Mongrain V, Ruan X, Dardente H, Fortier EE, Cermakian N. Clockdependent and independent transcriptional control of the two isoforms from the mouse Rorgamma gene. Genes Cells. 2008;13(12):1197-1210.

22. Schwarz EC, Kummerow C, Wenning AS, et al. Calcium dependence of $\mathrm{T}$ cell proliferation following focal stimulation. Eur J Immunol. 2007;37(10):2723-2733.

23. Hunt NH, Perris AD. Calcium and the control of circadian mitotic activity in rat bone marrow and thymus. J Endocrinol. 1974;62(3):451-462.

24. Pauly JE, Scheving LE, Burns ER, Tsai TH. Circadian rhythm in DNA synthesis in mouse thymus: effect of altered lighting regimens, restricted feeding and presence of Ehrlich ascites tumor. Anat Rec. 1976;184(3):275-284.

25. Levi FA, Canon C, Touitou Y, et al. Circadian rhythms in circulating $\mathrm{T}$ lymphocyte subtypes and plasma testosterone, total and free cortisol in five healthy men. Clin Exp Immunol. 1988;71(2):329-335.

26. Kirsch S, Thijssen S, Alarcon Salvador S, et al. T-cell numbers and antigen-specific T-cell function follow different circadian rhythms. $J$ Clin Immunol. 2012;32(6):1381-1389.

27. Born J, Lange T, Hansen K, Molle M, Fehm HL. Effects of sleep and circadian rhythm on human circulating immune cells. J Immunol. 1997;158(9):4454-4464

28. Dimitrov S, Benedict C, Heutling D, Westermann J, Born J, Lange T. Cortisol and epinephrine control opposing circadian rhythms in T cell subsets. Blood. 2009;113(21):5134-5143.

29. Depres-Brummer P, Bourin P, Pages N, Metzger G, Levi F. Persistent T lymphocyte rhythms despite suppressed circadian clock outputs in rats. Am J Physiol. 1997;273(6 Pt 2):R1891-R1899.

30. Mazzoccoli G, Sothern RB, Parrella P, et al. Comparison of circadian characteristics for cytotoxic lymphocyte subsets in non-small cell lung cancer patients versus controls. Clin Exp Med. 2012;12(3):181-194.

31. Mazzoccoli G, De Cata A, Greco A, et al. Aging related changes of circadian rhythmicity of cytotoxic lymphocyte subpopulations. J Circadian Rhythms. 2010;8:6.

32. Abo T, Kawate T, Itoh K, Kumagai K. Studies on the bioperiodicity of the immune response. I. Circadian rhythms of human T, B, and K cell traffic in the peripheral blood. J Immunol. 1981;126(4):1360-1363.

33. Ritchie AW, Oswald I, Micklem HS, Boyd JE, Elton RA, Jazwinska E, James K. Circadian variation of lymphocyte subpopulations: a study with monoclonal antibodies. $\mathrm{Br}$ Med J (Clin Res Ed). 1983;286(6380):1773-1775.

34. Fukuda R, Ichikawa Y, Takaya M, Ogawa Y, Masumoto A. Circadian variations and prednisolone-induced alterations of circulating lymphocyte subsets in man. Intern Med. 1994;33(12):733-738.

35. Cohen JJ. Thymus-derived lymphocytes sequestered in the bone marrow of hydrocortisone-treated mice. J Immunol. 1972;108(3):841-844.
36. Kawate T, Abo T, Hinuma S, Kumagai K. Studies of the bioperiodicity of the immune response. II. Co-variations of murine $\mathrm{T}$ and $\mathrm{B}$ cells and a role of corticosteroid. J Immunol. 1981;126(4):1364-1367.

37. Besedovsky L, Linz B, Dimitrov S, Groch S, Born J, Lange T. Cortisol increases CXCR4 expression but does not affect CD62L and CCR7 levels on specific T cell subsets in humans. Am J Physiol Endocrinol Metab. 2014;306(11):E1322-E1329.

38. Suzuki S, Toyabe S, Moroda T, et al. Circadian rhythm of leucocytes and lymphocytes subsets and its possible correlation with the function of the autonomic nervous system. Clin Exp Immunol. 1997;110(3):500-508.

39. Fernandes G, Halberg F, Yunis EJ, Good RA. Circadian rhythmic plaqueforming cell response of spleens from mice immunized with SRBC. $J$ Immunol. 1976;117(3):962-966.

40. Eskola J, Frey H, Molnar G, Soppi E. Biological rhythm of cell-mediated immunity in man. Clin Exp Immunol. 1976;26(2):253-257.

41. Kaplan MS, Byers VS, Levin AS, German DF, Fudenberg HH, Lecam LN. Circadian rhythm of stimulated lymphocyte blastogenesis. A 24 hour cycle in the mixed leukocyte culture reaction and with SKSD stimulation. J Allergy Clin Immunol. 1976;58(1 PT. 2):180-189.

42. Hiemke C, Brunner R, Hammes E, Muller H, Meyer zum Buschenfelde $\mathrm{KH}$, Lohse AW. Circadian variations in antigen-specific proliferation of human T lymphocytes and correlation to cortisol production. Psychoneuroendocrinology. 1995;20(3):335-342.

43. Bonacho MG, Cardinali DP, Castrillon P, Cutrera RA, Esquifino AI. Aging-induced changes in 24-h rhythms of mitogenic responses, lymphocyte subset populations and neurotransmitter and amino acid content in rat submaxillary lymph nodes during Freund's adjuvant arthritis. Exp Gerontol. 2001;36(2):267-282.

44. Esquifino AI, Selgas L, Arce A, Maggiore VD, Cardinali DP. Twentyfour-hour rhythms in immune responses in rat submaxillary lymph nodes and spleen: effect of cyclosporine. Brain Behav Immun. 1996;10(2):92-102.

45. Petrovsky N, McNair P, Harrison LC. Circadian rhythmicity of interferon-gamma production in antigen-stimulated whole blood. Chronobiologia. 1994;21(3-4):293-300.

46. Cuesta M, Boudreau P, Dubeau-Laramee G, Cermakian N, Boivin DB. Simulated night shift disrupts circadian rhythms of immune functions in humans. J Immunol. 2016;196(6):2466-2475.

47. Turner-Warwick M. Some connective tissue disorders of the lung. Postgrad Med J. 1988;64(753):497-504.

48. Nakamura Y, Nakano N, Ishimaru K, et al. Circadian regulation of allergic reactions by the masT-cell clock in mice. J Allergy Clin Immunol. 2014;133(2):568-575.

49. Dimitrov S, Lange T, Tieken S, Fehm HL, Born J. Sleep associated regulation of T helper 1/T helper 2 cytokine balance in humans. Brain Behav Immun. 2004;18(4):341-348.

50. Tanabe K, Kitagawa E, Wada M, et al. Antigen exposure in the late light period induces severe symptoms of food allergy in an OVA-allergic mouse model. Sci Rep. 2015;5:14424.

51. Lange T, Dimitrov S, Fehm HL, Born J. Sleep-like concentrations of growth hormone and cortisol modulate type1 and type 2 in-vitro cytokine production in human $\mathrm{T}$ cells. Int Immunopharmacol. 2006;6(2):216-225.

52. Daynes RA, Araneo BA. Contrasting effects of glucocorticoids on the capacity of T-cells to produce the growth factors interleukin 2 and interleukin 4. Eur J Immunol. 1989;19(12):2319-2325.

53. Yu X, Rollins D, Ruhn KA, et al. TH17 cell differentiation is regulated by the circadian clock. Science. 2013;342(6159):727-730.

54. Farez MF, Mascanfroni ID, Mendez-Huergo SP, et al. Melatonin contributes to the seasonality of multiple sclerosis relapses. Cell. 2015;162(6):1338-1352.

55. Bollinger T, Bollinger A, Skrum L, Dimitrov S, Lange T, Solbach W. Sleep-dependent activity of T cells and regulatory T-cells. Clin Exp Immunol. 2009;155(2):231-238.

56. Bollinger T, Bollinger A, Naujoks J, Lange T, Solbach W. The influence of regulatory $\mathrm{T}$ cells and diurnal hormone rhythms on $\mathrm{T}$ helper cell activity. Immunology. 2010;131(4):488-500. 


\section{Publish your work in this journal}

ChronoPhysiology and Therapy is an international, peer-reviewed, open access journal focusing on research into the cyclic variations and rhythmicity in physiological processes in the body and the research and development and optimal timing of administration of therapeutic targets to achieve improved outcomes and quality of life for the patient. The manuscript management system is completely online and includes a very quick and fair peer-review system. Visit http://www.dovepress.com/ testimonials.php to read real quotes from published authors. 